\title{
Puromycin-Sensitive Aminopeptidase
}

National Cancer Institute

\section{Source}

National Cancer Institute. Puromycin-Sensitive Aminopeptidase. NCI Thesaurus. Code C95861.

Puromycin-sensitive aminopeptidase (919 aa, 103 kDa) is encoded by the human NPEPPS gene. This protein plays a role in peptide cleavage. 